\title{
In vitro comparative analysis of cryopreservation of undifferentiated mesenchymal cells derived from human periodontal ligament
}

\author{
Rodrigo Gadelha Vasconcelos • Rodrigo Alves Ribeiro • \\ Marcelo Gadelha Vasconcelos • Kenio Costa Lima • \\ Carlos Augusto Galvão Barboza
}

Received: 7 June 2011/Accepted: 9 July 2011/Published online: 21 July 2011

(C) Springer Science+Business Media B.V. 2011

\begin{abstract}
Cryopreservation aims to cease all biological functions of living tissues in a reversible and controlled manner, i.e., to permit the recovery of cells by maintaining a high degree of their viability and functional integrity. The objective of this study was to evaluate in vitro the influence of cryopreservation on undifferentiated mesenchymal cells derived from the periodontal ligament of human third molars. Mesenchymal cells were isolated from six healthy teeth and cultured in $\alpha$-MEM medium supplemented with antibiotics and $15 \%$ FBS in a humid atmosphere
\end{abstract}

R. G. Vasconcelos · M. G. Vasconcelos

Postgraduate Program in Oral Pathology, Federal

University of Rio Grande do Norte, Natal, Rio Grande

do Norte, Brazil

\section{R. A. Ribeiro}

Postgraduate Program in Dentistry, Federal University of Rio Grande do Norte, Natal, Rio Grande do Norte, Brazil

K. C. Lima

Department of Dentistry, Federal University of Rio

Grande do Norte, Natal, Rio Grande do Norte, Brazil

C. A. G. Barboza $(\bowtie)$

Department of Morphology, Center of Biosciences, Federal University of Rio Grande do Norte, Campus Universitário, Av. Salgado Filho, 3000, Natal/RN CEP 59072-970, Brazil

e-mail: cbarboza@cb.ufrn.br with $5 \% \mathrm{CO}_{2}$ at $37^{\circ} \mathrm{C}$. The cells isolated from each tooth were divided into two groups: group I (fresh, non-cryopreserved cells) was immediately cultured, and group II was submitted to cryopreservation for 30 days. The rates of cell adhesion and proliferation were analyzed in the two groups by counting the cells adhered to the wells at 24, 48 and $72 \mathrm{~h}$ after plating. The number of cells per well was obtained by counting viable cells in a hemocytometer using the Trypan blue exclusion method. Differences between groups at each time point were evaluated by the Wilcoxon test. The Friedman test was used to determine differences between time points and, if detected, the Wilcoxon test with Bonferroni correction was applied. The results showed no significant difference in the in vitro growth capacity of undifferentiated mesenchymal cells between the two groups. In conclusion, cryopreservation for 30 days had no influence on periodontal ligament mesenchymal cells.

Keywords Cryopreservation - Cell culture technique - Teeth · Periodontal ligament . Mesenchymal stem cells

\section{Introduction}

Undifferentiated mesenchymals cells, or stem cells, are characterized by the ability of self-renewal and 
the production of at least on highly specialized cell type. There are two types of stem cells: pluripotent embryonic stem cells that are derived from the embryoblast during the blastula phase and are able to give origin to all cell lines, and multipotent or unipotent cells, called adult stem cells, which are able to give origin to specific cell types (Gronthos et al. 2006).

Undifferentiated mesenchymal cells have also been isolated from oral tissues, such as dental pulp (Gronthos et al. 2000, 2002; Shi et al. 2001; Miura et al. 2003; Shi and Gronthos 2003; Sloan and Smith 2007) and periodontal ligament (Seo et al. 2004; Akizuki et al. 2005; Chen et al. 2006; Nagatomo et al. 2006; Gronthos et al. 2006). The identification of this cell population in dental tissues has raised interest in the regenerative potential of these cells and their application to tissue engineering or bioengineering (Leon et al. 2007). Tissue engineering has gained importance as an interdisciplinary field which applies the principles of engineering and life sciences to the development of biological substitutes that are able to restore, maintain, or improve tissue function (Langer and Vacanti 1993). Bioengineering consists of the fabrication or regeneration of damaged or lost tissues, including bone tissue, as a result of degenerative diseases, trauma, cancer or periodontal disease, and is based on cell therapy involving the use of undifferentiated mesenchymal cells combined or not with biomaterials (Silvério et al. 2008).

The need to maintain organs alive for a long period of time without the loss of cell function has led to the investigation of cryopreservation (Oh et al. 2005). So far, it remains unknown to what extent stem cellderived cells are able to maintain their differentiation capacity and morphofunctional properties after a long period of cryopreservation. This knowledge is important to evaluate the long-term storage potential of these cells and their subsequent use in tissue regeneration therapies (Papaccio et al. 2006).

In view of the important role of undifferentiated mesenchymal cells in the processes of periodontal tissue reconstruction, the present study evaluated the influence of cryopreservation for 30 days on the adhesion and proliferative capacity of undifferentiated mesenchymal cells derived from the periodontal ligament of human third molars at 24, 48 and $72 \mathrm{~h}$ by comparing cryopreserved cells with freshly cultured cells.

\section{Methods}

Tooth extraction and processing

The study was approved by the Ethics Committee of the Federal University of Rio Grande do Norte (protocol number 018/10, approval number 080/ 2010). All volunteers signed a free informed consent form.

Six human third molars were obtained from different patients of both genders, ranging in age from 18 to 30 years, who presented good systemic and oral health. The teeth were immediately stored in $50-\mathrm{mL}$ Falcon tubes $\left(\mathrm{TPP}^{\circledR}\right.$, Switzerland) containing $5 \mathrm{~mL} \alpha$-MEM medium (Gibco, USA) under hypothermic conditions $\left(4^{\circ} \mathrm{C}\right)$. Next, the teeth were immersed in maintenance solution containing $\alpha$-MEM medium supplemented with $10,000 \mathrm{IU} / \mathrm{mL}$ penicillin, $10,000 \mu \mathrm{g} / \mathrm{mL}$ streptomycin, $100 \mathrm{mg} / \mathrm{mL}$ gentamicin, and $250 \mu \mathrm{g} / \mathrm{mL}$ amphotericin B (all antibiotics were from Gibco, USA) to eliminate possible contamination.

Isolation of undifferentiated mesenchymal cells from periodontal ligament

The periodontal ligament was removed by gently scraping the root surface with a scalpel, followed by enzymatic digestion with $3 \mathrm{mg} / \mathrm{mL}$ collagenase I (Gibco) and $4 \mathrm{mg} / \mathrm{mL}$ dispase (Gibco) for $1 \mathrm{~h}$ at $37^{\circ} \mathrm{C}$. The solution was then aspirated, filtered through a $70-\mu \mathrm{m}$ filter (BD Falcon, USA), and centrifuged at $1,200 \mathrm{rpm}$ for $5 \mathrm{~min}$. The precipitated cells were resuspended and cultured.

Culture of periodontal ligament-derived undifferentiated mesenchymal cells

Each cell sample was cultured in $25-\mathrm{cm}^{2}$ cell culture flasks (BD Falcon) containing basic $\alpha$-MEM medium supplemented with $15 \%$ fetal bovine serum (FBS; Gibco). The cultures were maintained at $37^{\circ} \mathrm{C}$ in a $5 \% \mathrm{CO}_{2}$ atmosphere and the medium was changed at intervals of 3 days until $70-90 \%$ confluence was reached. After isolation and expansion, the periodontal ligament cells were divided into two groups (Fig. 1): (1) Control group: cells were cultured immediately and third-passage (P3) cells were transferred to three 6-well plates (one well per tooth) for 
Fig. 1 Culture of undifferentiated mesenchymal cells derived from periodontal ligament in the control (left) and experimental (right) groups

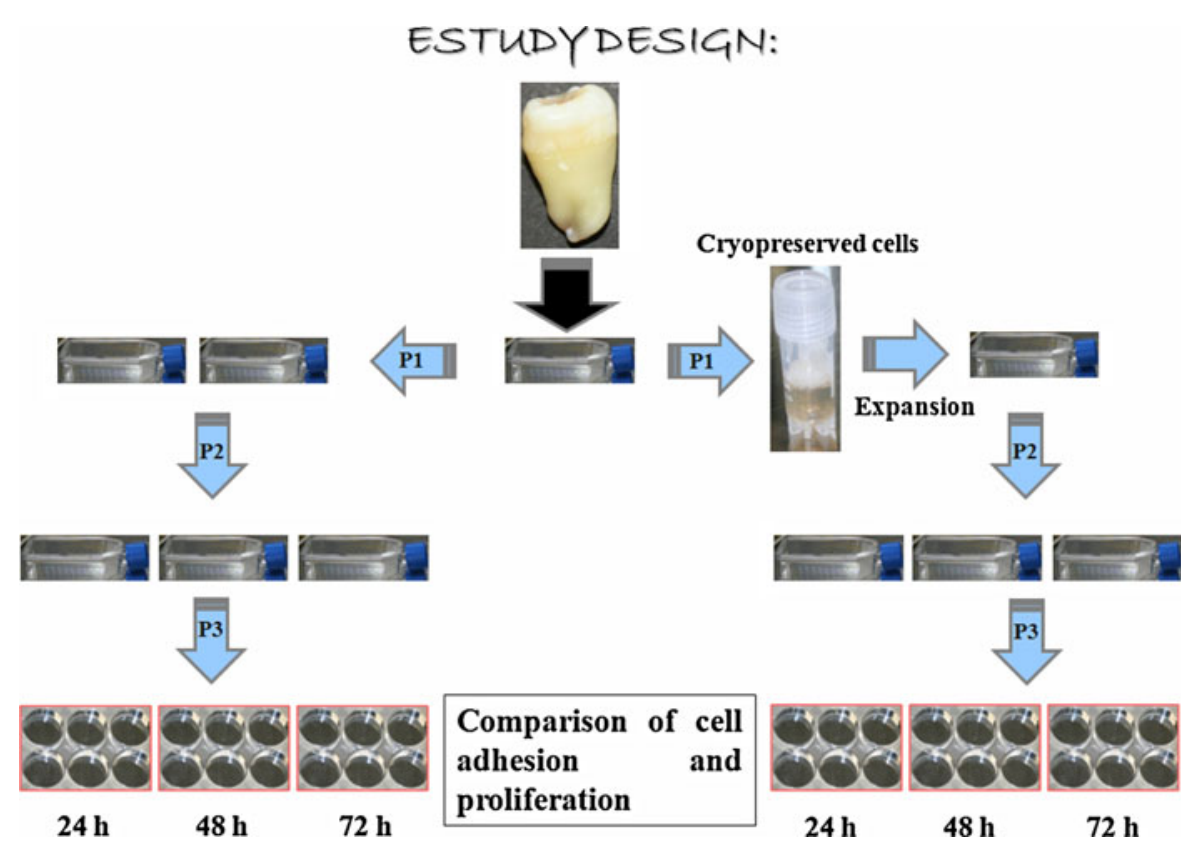

analysis. (2) Experimental group: first-passage (P1) cells were cryopreserved for 30 days and then cultured until P3, when the cells were transferred to three 6-well plates (one well per tooth) for analysis.

After the third passage, each cell sample was cultured in 6-well plates $\left(\mathrm{TTP}^{\circledR}\right)$ at a density of $1 \times 10^{4}$ cells per well. The number of cells was determined after 24,48 and $72 \mathrm{~h}$ for analysis of cell adhesion and proliferation (Fig. 1).

In order to confirm the multi-lineage differentiation potential of periodontal ligament cells, aliquots of P1 cells were cultured in osteogenic, chondrogenic, or adipogenic differentiation media (StemPro ${ }^{\circledR}$ Differentiation Kits, Invitrogen, USA) for up to 21 days. By light microscopy, the cells showed typical osteoblast/ osteocyte, chondroblast, and adipocyte morphology and produced characteristic extracellular matrix components.

Cryopreservation of periodontal ligament-derived undifferentiated mesenchymal cells

A suspension $(1 \mathrm{~mL})$ of each first-passage cell sample containing $1 \times 10^{6}$ cells per cryogenic vial was frozen. The cells were stored in FBS containing $10 \%$ dimethylsulfoxide (DMS) in 2-mL cryogenic vials $\left(\mathrm{TTP}^{\circledR}\right)$ and then submitted to the cryopreservation protocol: $2 \mathrm{~h}$ at $4^{\circ} \mathrm{C}, 18 \mathrm{~h}$ at $-20^{\circ} \mathrm{C}$, and then at $-85^{\circ} \mathrm{C}$ for 30 days. After this period, the cells were rapidly thawed in a water bath at $37^{\circ} \mathrm{C}$ for subsequent cell culture.

Analysis of cell adhesion and proliferation rates

Cell adhesion and proliferation were analyzed and growth curves were constructed for the different groups by determining the number of cells adhered to the plastic surface of the cell culture plate at 24,48 and $72 \mathrm{~h}$ after plating. The number of cells collected from each well was obtained by counting viable cells in a hemocytometer using the Trypan blue (Gibco) exclusion method.

Statistical analysis

Each cell count corresponds to the mean of six samples (six wells per time interval per tooth). These means, in absolute values, were $\log 10$ transformed to reduce variability and the data were submitted to nonparametric analysis. Differences between groups at each time point $(24,48$ and $72 \mathrm{~h}$ ) were evaluated by the Wilcoxon test. The Friedman test was used to evaluate differences between time points and, if detected, the Wilcoxon test with Bonferroni correction was applied to determine where the difference occurred. A level of significance of $5 \%$ was adopted. 


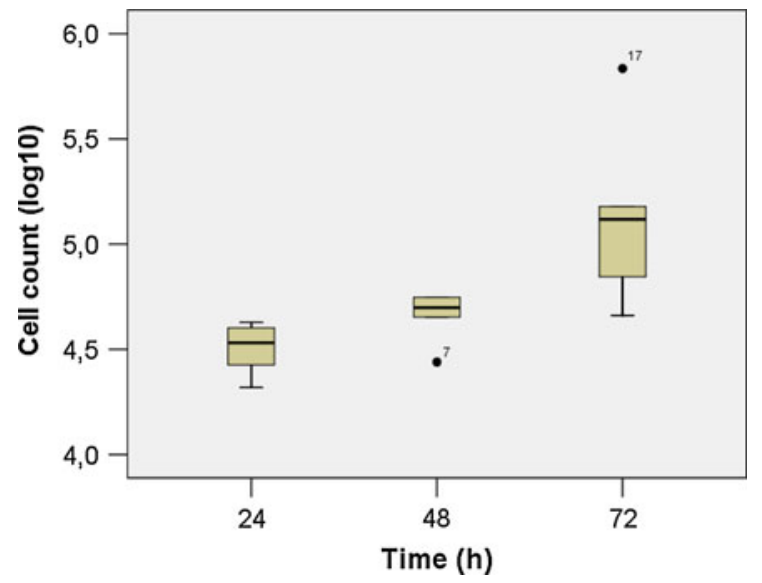

Fig. 2 Box plot of the growth pattern (adhesion and proliferation) of immediately cultured undifferentiated mesenchymal cells derived from the periodontal ligament of human third molars at different times after plating

\section{Results}

Adhesion and proliferation of fresh cells (cultured immediately after isolation)

Figure 2 illustrates the growth pattern of the six samples of fresh undifferentiated mesenchymal cells over the period studied. A significant difference $(P=0.002)$ was observed between the three time intervals $(24 / 48,24 / 72$, and 48/72 h). These results demonstrate that undifferentiated mesenchymal cells

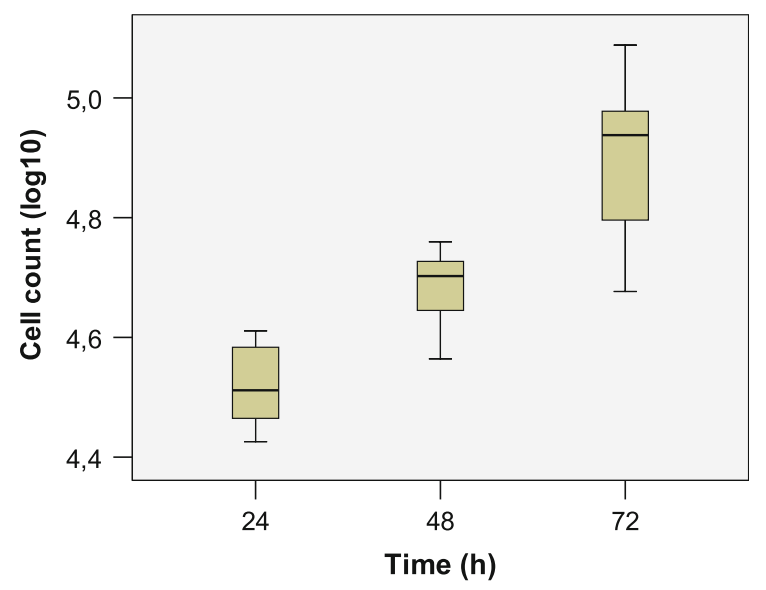

Fig. 3 Box plot of the growth pattern of cryopreserved undifferentiated mesenchymal cells derived from the periodontal ligament of human third molars at different times after plating derived from the periodontal ligament of human third molars are able to grow in vitro when the culture conditions are adequate.

Adhesion and proliferation of cryopreserved cells

Figure 3 shows the growth pattern of the six samples of cryopreserved undifferentiated mesenchymal cells over the period studied. A significant difference $(P=0.002)$ was observed between the three time intervals $(24 / 48,24 / 72$, and 48/72 h). These results show that periodontal ligament-derived undifferentiated mesenchymal cells maintain their in vitro proliferative capacity after cryopreservation for 30 days.

Comparison of adhesion and proliferation between fresh and cryopreserved cells

Comparison of the growth pattern of the six samples of fresh and cryopreserved mesenchymal cells over the period studied is shown in Figs. 4, 5, and 6. No significant difference between groups was observed at any of the time intervals studied (24, 48, and $72 \mathrm{~h})$. These results demonstrate that cryopreservation did not alter the growth pattern of undifferentiated mesenchymal cells derived from the periodontal ligament of human third molars, i.e., in vitro cell viability was the same in the two groups. Variability

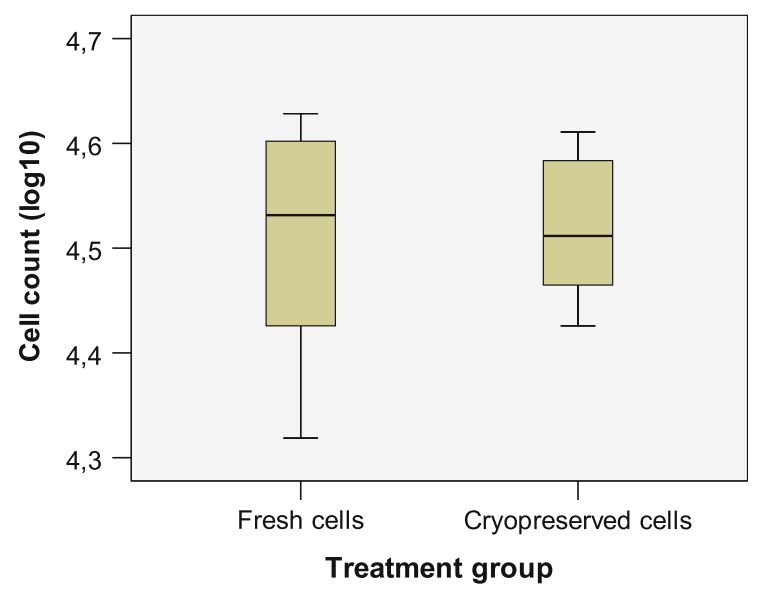

Fig. 4 Comparative box plot analysis of adhesion and proliferation between fresh and cryopreserved undifferentiated mesenchymal cells derived from periodontal ligament of human third molars at $24 \mathrm{~h}$ after plating. There was no significant difference between groups 


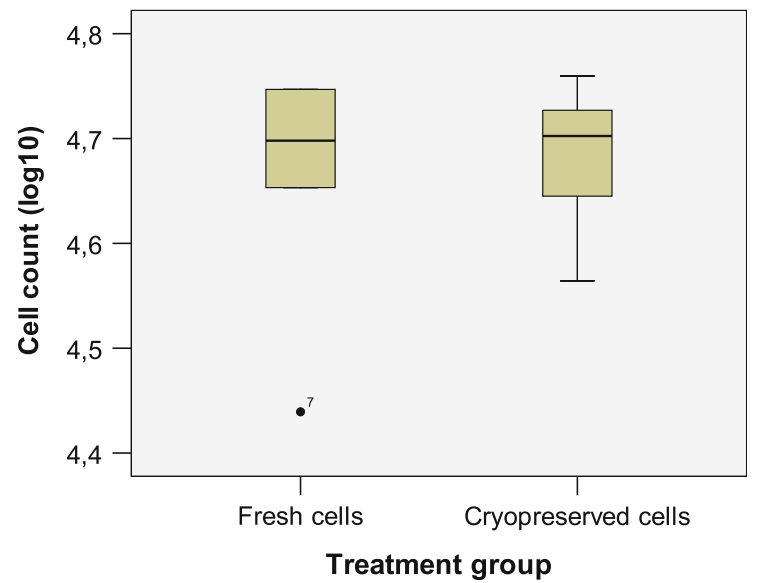

Fig. 5 Comparative box plot analysis of adhesion and proliferation between fresh and cryopreserved undifferentiated mesenchymal cells derived from periodontal ligament of human third molars at $48 \mathrm{~h}$ after plating. There was no significant difference between groups

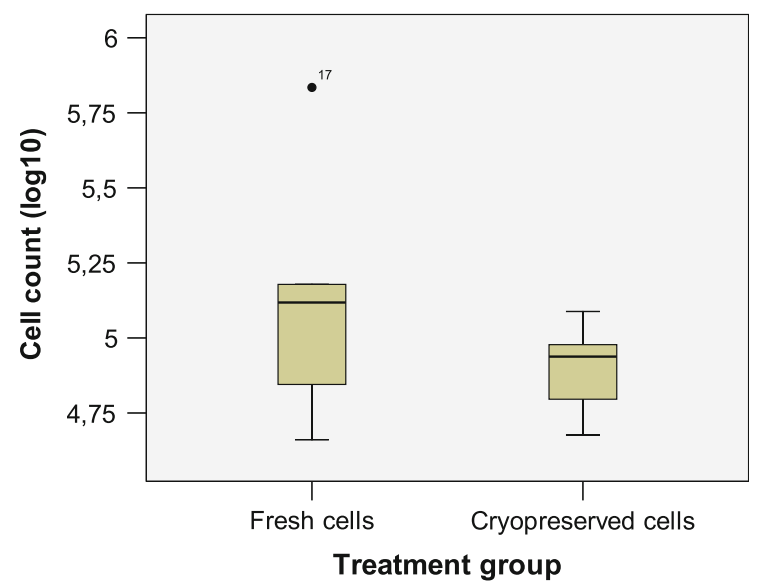

Fig. 6 Comparative box plot analysis of adhesion and proliferation between fresh and cryopreserved undifferentiated mesenchymal cells derived from periodontal ligament of human third molars at $72 \mathrm{~h}$ after plating. There was no significant difference between groups

was lower in the group of cryopreserved cells at all time intervals studied, particularly at 24 and $72 \mathrm{~h}$.

Growth curve of fresh and cryopreserved cells

Analysis of the growth curve of fresh and cryopreserved cells showed a linear trend for the two types of cells over the period studied, with no significant difference between groups (Fig. 7).

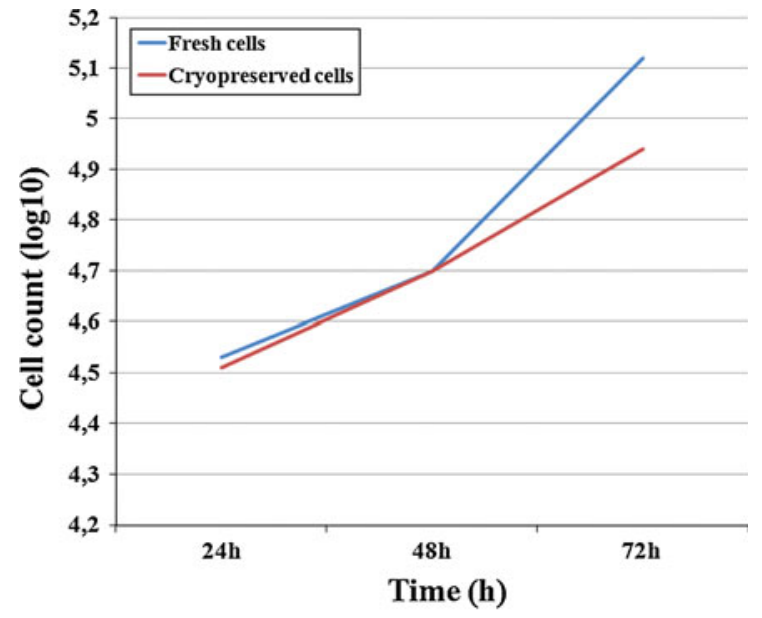

Fig. 7 Growth curve of fresh and cryopreserved undifferentiated mesenchymal cells derived from periodontal ligament of human third molars over the period studied

\section{Discussion}

Studies conducted by a group of the National Institute of Dental and Craniofacial Research (NIDCR, USA) have demonstrated the existence of adult stem cells in the pulp of deciduous and permanent teeth and in the periodontal ligament, which maintain a high differentiation capacity. This group of researchers developed a protocol for the isolation and culture of dental stem cells and a similar protocol was used in the present study (Gronthos et al. 2000, 2002; Miura et al. 2003; Seo et al. 2004). According to this protocol, stem cells were separated from the extracellular matrix of the pulp and periodontal ligament and seeded onto cell culture plates containing specific medium. The cells were then incubated at $37^{\circ} \mathrm{C}$ in a $5 \% \mathrm{CO}_{2}$ atmosphere to determine their proliferative capacity and the formation of colonies. Clusters containing more than 50 cells were defined as colonies.

According to the literature, the periodontal ligament is an easily available and efficient autogenous source of undifferentiated mesenchymal cells, which are able to expand and to differentiate into fibroblastic, cementoblastic and osteoblastic cells. The plausibility of tissue engineering based on the use of stem cells for periodontal regeneration is supported by animal studies showing that periodontal ligament cells cultured in vitro can be successfully reimplanted into periodontal defects, promoting periodontal 
regeneration (Isaka et al. 2001; Akizuki et al. 2005; Hasegawa et al. 2005; Ivanovski et al. 2006). Undifferentiated mesenchymal cells can be expanded into a framework, or can be injected in vivo directly into the site of injury (Chen and Jin 2010).

Undifferentiated mesenchymal cells derived from the human periodontal ligament have been shown to be suitable for the regeneration of periodontal structures, or even for large reconstructions of craniomaxillofacial deformities (Huang 2008; Chen and Jin 2010). This fact highlights the importance of cryopreservation of these cells for subsequent clinical use, promoting the acceleration of the tissue repair process in patients with periodontal diseases (Oh et al. 2005; Seo et al. 2005; Temmerman et al. 2006; Zhang et al. 2006). Several studies have shown that undifferentiated mesenchymal cells isolated from the periodontal ligament, dental pulp, or apical papilla can be cryopreserved successfully, guaranteeing their viability after thawing (Temmerman et al. 2008; Woods et al. 2009; Ding et al. 2010), in agreement with the present study. These findings suggest the feasibility of the use of dental tissue-derived mesenchymal cells for banking as proposed by $\mathrm{Oh}$ et al. (2005), Perry et al. (2008), and Woods et al. (2009).

Knowledge about the principles that guide the process of cryopreservation is of the utmost importance for a successful procedure. Despite a large number of studies on the cryopreservation of teeth (Bartlett and Reade 1972; Price and Cserepfalvi 1972; Schwartz and Andreasen 1983; Schwartz et al. 1985; Schwartz and Rank 1986; Schwartz 1986; Politis et al. 1995; Laureys et al. 2001; Kawasaki et al. 2004), some questions regarding the possible reactions of dental tissues after cryopreservation remain unanswered. This is probably one of the reasons why transplantation of cryopreserved teeth is still not widely accepted. The authors cited above concluded that a simpler and more precise in vitro test that would permit a detailed analysis of the freezing and cooling method is needed in order to evaluate the effects of cryoprotective agents on the cells studied. In this respect, the objective of the present study was to investigate in vitro the effect of a standardized cryopreservation procedure on undifferentiated mesenchymal cells derived from periodontal ligament by evaluating the adhesion and proliferation of these cells (Temmerman et al. 2008).
The survival and maintenance of function of periodontal cells seem to be essential for the repair process and for a good prognosis of the grafted tooth. Literature data and the results of the present study suggest that cryopreservation has no negative influence on the in vitro adhesion or proliferation of periodontal ligament cells when a controlled freezing method is used. The addition of a cryoprotective agent (DMSO) guarantees the survival of periodontal mesenchymal cells. Therefore, the prognosis of transplanted cryopreserved teeth seems to be similar to that of immediately transplanted teeth (Temmerman et al. 2006).

According to Basdra and Komposch (1997) and Temmerman et al. (2008), fibroblasts extracted from human periodontal ligament show intense alkaline phosphatase staining, a finding indicating that these cells are able to differentiate into osteoblasts and cementoblasts. This characteristic emphasizes the potential use of these cells in the repair of periodontal structures. In most in vitro studies using fibroblasts extracted from human periodontal ligament, these cells expressed alkaline phosphatase activity at a much higher level than gingival fibroblasts (Somerman et al. 1988; Arceo et al. 1991; Ogata et al. 1995; Giannopoulou and Cimasoni 1996; Gao et al. 1999; Kawasaki et al. 2004). Temmerman et al. (2008) investigated the influence of cryopreservation of periodontal ligament fibroblasts for $24 \mathrm{~h}$ on membrane integrity (cell viability), growth capacity, and alkaline phosphatase expression. The results showed no influence of cryopreservation on the parameters studied. It should be noted that membrane integrity testing reveals the membrane status of cells at a certain time, but does not offer insights into the linear behavior of these cells (Stevenson et al. 2004). To study the long-term effects of cryopreservation of periodontal ligament mesenchymal cells, it would be more adequate to evaluate the growth capacity of these cells as done in the present study at intervals of 24, 48 and $72 \mathrm{~h}$.

Comparison of adhesion and proliferation showed no differences between the groups studied (cells cultured immediately after isolation and cryopreserved cells). These results agree with the findings of Oh et al. (2005), Seo et al. (2005), Perry et al. (2008), Temmerman et al. (2008, 2010), Woods et al. (2009) and Ding et al. (2010), indicating that the process of 
freezing and thawing has no negative influence on the growth capacity of periodontal cells.

There is consensus in the literature that tissues submitted to cryopreservation should be protected by the addition of cryoprotective agents. In addition, an adequate freezing rate needs to be applied throughout the process to prevent the formation of intracellular ice crystals. Woods et al. (2009) reported that cryopreservation of whole teeth for the isolation of periodontal ligament mesenchymal cells, which can be expanded and used clinically, does not provide reliable or repeatable results. A cell cryopreservation protocol instead of freezing the whole tooth was therefore used in the present study. DMSO (10\%) was added as a cryoprotective agent and the cells were submitted to the following process of cryopreservation as reported by Temmerman et al. (2010), Woods et al. (2009) and Ding et al. (2010): $2 \mathrm{~h}$ at $4^{\circ} \mathrm{C}, 18 \mathrm{~h}$ at $-20^{\circ} \mathrm{C}$, and then at $-85^{\circ} \mathrm{C}$ for a period of 30 days.

DMSO has been widely used for the cryopreservation of dental tissues or dental stem cells (Seo et al. 2005; Papaccio et al. 2006). This agent has provided favorable results in terms of cell viability and proliferative capacity after cryopreservation of cells for a period of 30 days (Woods et al. 2009), in agreement with the findings of the present study. In addition, Ding et al. (2010) tested three cryoprotective agents (10\% DMSO plus $90 \%$ FBS; $10 \%$ glycerol plus $90 \%$ FBS, and $10 \%$ ethylene glycol plus $90 \%$ FBS) for the cryopreservation of undifferentiated mesenchymal cells extracted from the apical papilla of human third molars for a period of 6 months, and found no significant differences in the biological properties (cell viability, colony-forming efficiency, and cell proliferation) of these cells. In agreement with these findings, Woods et al. (2009) showed that DMSO at concentrations of $0.5,1.0$ and $1.5 \mathrm{M}$ yielded better results in terms of cell viability than propyleneglycol or ethylene glycol at the same concentrations.

With respect to the freezing temperature used in the present study $\left(-85^{\circ} \mathrm{C}\right)$, we emphasize the simplicity of the method since it does not require the use of liquid nitrogen at a temperature of $-196^{\circ} \mathrm{C}$. This fact makes the process technically simpler and less costly, and guarantees results similar to those obtained with liquid nitrogen as demonstrated in the study of Woods et al. (2009), who cryopreserved undifferentiated mesenchymal cells derived from dental pulp for 6 months at the two temperatures and observed an identical differentiation capacity in the two groups.

In the present study, quantitative statistical analysis revealed an increase in cell adhesion and proliferation at the different time intervals (24, 48 and $72 \mathrm{~h}$ ) in the two groups studied (fresh and cryopreserved cells). Similar results have been reported by $\mathrm{Oh}$ et al. (2005), Seo et al. (2005) and Temmerman et al. (2006). In addition, a significant difference in these rates was observed between the three time intervals in each group. These finding not only show the expressive capacity of this cell type to grow and multiply under adequate cell culture conditions (Gronthos et al. 2006; Huang et al. 2010), but also suggest the potential use of these cells in future clinical applications (Zhang et al. 2006; Perry et al. 2008).

Pairwise comparison between groups by the Wilcoxon test showed a significant difference at the three time intervals $(24,48$ and $72 \mathrm{~h}$ ). These findings demonstrated that the process of cryopreservation did not alter the growth pattern, i.e., fresh and cryopreserved undifferentiated mesenchymal cells derived from the periodontal ligament of human third molars are viable in vitro. Similar results have been reported by Temerman et al. $(2008,2010)$ and Ding et al. (2010). Variability was lower in the group of cryopreserved cells, particularly at 24 and $72 \mathrm{~h}$, suggesting that the process selected cell colonies able to survive cryopreservation.

The present results confirm the feasibility of the use of human tooth-derived stem cells for banking (Perry et al. 2008). Further studies are needed to optimize the process of cryopreservation of these cells for future clinical applications (Woods et al. 2009), whose findings would provide new perspectives for periodontal regenerative therapy and bioengineering by combining this type of cell with biomaterials such as titanium (Cochran et al. 1994; Gay et al. 2007) or hydroxyapatite (Miura et al. 2003; Shi et al. 2005; Sonoyama et al. 2006).

\section{Conclusion}

Cryopreservation under controlled conditions for a period of 30 days had no influence on the adhesion or proliferative capacity of undifferentiated mesenchymal 
cells derived from the periodontal ligament of human third molars. These cells showed a similar in vitro growth capacity as non-cryopreserved (fresh) cells.

Acknowledgments The authors thank BioPol (Laboratório de Biotecnologia de Polímeros Naturais, Departamento de Bioquímica, UFRN) for kindly providing the support on the cell culture equipment.

\section{References}

Akizuki T, Oda S, Komaki M, Tsuchioka H, Kawakatsu N, Kikuchi A et al (2005) Application of periodontal ligament cell sheet for periodontal regeneration: a pilot study in beagle dogs. J Periodontal Res 40:245-251

Arceo N, Sauk JJ, Moehring J, Foster RA, Somerman MJ (1991) Human periodontal cells initiate mineral-like nodules in vitro. J Periodontol 62:499-503

Bartlett PF, Reade PC (1972) Cryopreservation of developing teeth. Cryobiology 9:205-211

Basdra EK, Komposch G (1997) Osteoblast-like properties of human periodontal ligament cells:an in vitro analysis. Eur J Orthod 19:615-621

Chen FM, Jin Y (2010) Periodontal tissue engineering and regeneration: current approaches and expanding opportunities. Tissue Eng Part B Rev 16:219-255

Chen SC, Marino V, Gronthos S, Bartold PM (2006) Location of putative stem cells in human periodontal ligament. J Periodontal Res 41:547-553

Cochran D, Simpson J, Weber H, Buser D (1994) Attachment and growth of periodontal cells on smooth and rough titanium. Int J Oral Maxillofac Implants 9:289-297

Ding G, Wang W, Liu Y, An Y, Zhang C, Shi S et al (2010) Effect of cryopreservation on biological and immunological properties of stem cells from apical papilla. J Cell Physiol 223:415-422

Gao J, Symons AL, Haase H, Bartold PM (1999) Should cementoblasts express alkaline phosphatase activity? Preliminary study of rat cementoblasts in vitro. J Periodontol 70:951-959

Gay IC, Chen S, MacDougall M (2007) Isolation and characterization of multipotent human periodontal ligament stem cells. Orthod Craniofac Res 10:149-160

Giannopoulou C, Cimasoni G (1996) Functional characteristics of gingival and periodontal ligament fibroblasts. J Dent Res 75:895-902

Gronthos S, Mankani M, Brahim J et al (2000) Postnatal human dental pulp stem cells (DPSCs) in vitro and in vivo. Proc Natl Acad Sci 97:13625-13630

Gronthos S, Brahim J, Li W, Fisher LW, Cherman N, Boyde A, DenBesten P, Robey PG, Shi S (2002) Stem cell properties of human dental pulp stem cells. J Dent Res 81:531-535

Gronthos S, Mrozik M, Shi S, Bartold PM (2006) Ovine periodontal ligament stem cells: isolation, characterization, and differentiation potential. Calcif Tissue Int 79:310-317
Hasegawa M, Yamoto M, Kikuchi A, Okano T, Ishikawa I (2005) Human periodontal ligament sheets can regenerate periodontal ligament tissue in an athymic rat model. Tissue Eng 11:469-478

Huang GT (2008) A paradigm shift in endodontic management of immature teeth: conservation of stem cells for regeneration. J Dent 36:379-386

Huang YH, Yang JC, Wang CW, Lee SY (2010) Dental stem cells and tooth banking for regenerative medicine. J Exp Clin Med 2:111-117

Isaka J, Ohazama A, Kobayashi M, Nagashima C, Takiguchi T, Kawasaki H, Tachikawa T, Hasegawa K (2001) Participation of periodontal ligament cells with regeneration of alveolar bone. J Periodontol 72:314-323

Ivanovski S, Gronthos S, Shi S, Bartold PM (2006) Stem cells in the periodontal ligament. Oral Dis 12:358-363

Kawasaki N, Hamamoto Y, Nakajima T, Irie K, Ozawa H (2004) Periodontal regeneration of transplanted rat molars after cryopreservation. Arch Oral Biol 49:59-69

Langer R, Vacanti JP (1993) Tissue engineering. Science 260:920-926

Laureys W, Beele H, Cornelissen R, Dermaut L (2001) Revascularization after cryopreservation and autotransplantation of immature and mature apicoectomized teeth. Am J Orthod Dentofacial Orthop 119:346-352

Leon ER, Iwasaki K, Komaki M, Kojima T, Ishikawa I (2007) Osteogenic effect of interleukin-11 and synergism with ascorbic acid in human periodontal ligament cells. J Periodont Res 42:527-535

Miura M, Gronthos S, Zhao M, Lu B, Fisher LW, Robey PG (2003) SHED: stem cells from human exfoliated deciduous teeth. Proc Natl Acad Sci USA 100:5807-5812

Nagatomo K, Komaki M, Sekiya I, Sakaguchi Y, Noguchi K, Oda $S$ et al (2006) Stem cell properties of human periodontal ligament cells. J Periodont Res 41:303-310

Ogata Y, Niisato N, Sakurai T, Furuyama S, Sugiya H (1995) Comparison of the characteristics of human gingival fibroblasts and periodontal ligament cells. J Periodontol 66:1025-1031

Oh YH, Che ZM, Hong JC, Lee EJ, Lee SJ, Kim J (2005) Cryopreservation of human teeth for future organization of a tooth bank-A preliminary study. Cryobiology 51:322-329

Papaccio G, Graziano A, D’Aquino R, Graziano MF, Pirozzi G, Menditti D et al (2006) Long-term cryopreservation of dental pulp stem cells (SBP-DPSCs) and their differentiated osteoblasts: a cell source for tissue repair. J Cell Physiol 208:319-325

Perry BC, Perry BC, Zhou D, Wu X, Yang FC, Byers MA et al (2008) Collection, cryopreservation, and characterization of human dental pulp-derived mesenchymal stem cells for banking and clinical use. Tissue Eng Part C Methods 14:149-156

Politis C, Vrielinck L, Schepers S, Lambrichts I (1995) Cryopreservation of teeth. Organizational aspects of a tissue bank for tooth tissues. Acta Stomatol Belg 92:149-154

Price PJ, Cserepfalvi M (1972) Pulp viability and the homotransplantation of frozen teeth. J Dent Res 51:39-43 
Schwartz O (1986) Cryopreservation as long-term storage of teeth for transplantation or replantation. Int J Oral Maxillofac Surg 15:30-32

Schwartz O, Andreasen JO (1983) Cryopreservation of mature teeth before replantation in monkeys (I). Effect of different cryoprotective agents and freezing devices. Int J Oral Surg 12:425-436

Schwartz O, Rank CP (1986) Autotransplantation of cryopreserved tooth in connection with orthodontic treatment. Am J Orthod Dentofacial Orthop 90:67-72

Schwartz O, Andreasen JO, Greve T (1985) Cryopreservation before replantation of mature teeth in monkeys. (II). Effect of preincubation, different freezing and equilibration rates and endodontic treatment upon periodontal healing. Int J Oral Surg 14:350-361

Seo BM, Miura M, Gronthos S, Bartold PM, Batouli S, Brahim J, Young M, Robey PG, Wang CY, Shi S (2004) Investigation of multipotent stem cells from human periodontal ligament. Lancet 364:149-155

Seo BM, Miura M, Sonoyama W, Coppe C, Stanyon R, Shi S (2005) Recovery of stem cells from cryopreserved periodontal ligament. J Dent Res 84:907-912

Shi S, Gronthos S (2003) Perivascular niche of postnatal mesenchymal stem cells in human bone marrow and dental pulp. J Bone Miner Res 18:696-704

Shi S, Robey PG, Gronthos S (2001) Comparison of human dental pulp and bone marrow stromal stem cells by cDNA microarray analysis. Bone 29:532-539

Shi S, Bartold PM, Miura M, Seo BM, Robey PG, Gronthos S (2005) The efficacy of mesenchymal stem cells to regenerate and repair dental structures. Orthod Craniofacial Res 8:191-199

Silvério KG, Benatti BB, Casati MZ, Sallum EA, Nociti FH Jr (2008) Stem cells: potential therapeutics for periodontal regeneration. Stem Cell Rev 4:13-19
Sloan AJ, Smith AJ (2007) Stem cells and the dental pulp: potential roles in dentine regeneration and repair. Oral Dis 13:151-157

Somerman MJ, Archer SY, Imm GR, Foster RA (1988) A comparative study of human periodontal ligament cells and gingival fibroblasts in vitro. J Dent Res 67:66-70

Sonoyama W, Liu Y, Fang D, Yamaza T, Seo BM, Zhang C et al (2006) Mesenchymal stem cell-mediated functional tooth regeneration in swine. PLoS One 79:1-8

Stevenson DJ, Morgan C, Goldie E, Connel G, Grant MH (2004) Cryopreservation of viable hepatocyte monolayers in cryoprotectant media with high serum content: metabolism of testosterone and kaempherol post-cryopreservation. Cryobiology 49:97-113

Temmerman L, De Pauw GA, Beele H, Dermaut LR (2006) Tooth transplantation and cryopreservation: state of the art. Am J Orthod Dentofacial Orthop 129:691-695

Temmerman L, Dermaut LR, Mil MD, Maele GV, Beele H, De Pauw GA (2008) Influence of cryopreservation on human periodontal ligament cells in vitro. Cell Tissue Bank 9:11-18

Temmerman L, Beele H, Dermaut LR, Maele GV, De Pauw EGAM (2010) Influence of cryopreservation on the pulpal tissue of immature third molars in vitro. Cell Tissue Bank 11:281-289

Woods EJ, Perry BC, Hockema JJ, Larson L, Zhou D, Goebel WS (2009) Optimized cryopreservation method for human dental pulp-derived stem cells and their tissues of origin for banking and clinical use. Cryobiology 59:150-157

Zhang W, Walboomers XF, Shi S, Fan M, Jansen JA (2006) Multilineage differentiation potential of stem cells derived from human dental pulp after cryopresenvation. Tissue Eng 12:2813-2823 